\title{
Adherence to guidelines for surveillance colonoscopy in patients with ulcerative colitis at a Canadian quaternary care hospital
}

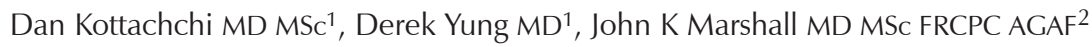

\begin{abstract}
D Kottachchi, D Yung, JK Marshall. Adherence to guidelines for surveillance colonoscopy in patients with ulcerative colitis at a Canadian quaternary care hospital. Can J Gastroenterol 2009;23(9):613-617.
\end{abstract}

BACKGROUND: Patients with ulcerative colitis (UC) are at high risk of colonic dysplasia. Therefore, surveillance colonoscopy to detect early dysplasia has been endorsed by many professional organizations.

OBJECTIVES: To determine whether gastroenterologists at Hamilton Health Sciences (Hamilton, Ontario) adhere to recommendations for UC surveillance issued by the Canadian Association of Gastroenterology and to retrospectively assess the incidence and type of dysplasia found and the subsequent outcome of patients with dysplasia (ie, colorectal cancer [CRC], colectomy, dysplasia recurrence).

METHODS: A retrospective chart review of all patients with UC undergoing colonoscopy screening at Hamilton Health Sciences from January 1980 to January 2005, was performed. Patients were classified by the extent of colonic disease: limited left-sided colitis (LSC), pancolitis and any disease extent with concurrent primary sclerosing cholangitis.

RESULTS: A total of 141 patients fulfilled eligibility criteria. They underwent 921 endoscopies, including 453 for surveillance, which were performed by 20 endoscopists. Overall, screening was performed on $90 \%$ of patients, and surveillance at the appropriate time in $74 \%$. There was a statistically significant increase in the mean number of biopsies per colonoscopy after the guidelines were published $(\mathrm{P}<0.01$ for all categories). Colonic dysplasia was detected in 24 of 141 patients (17.0\%), with 17 of 24 (70.8\%) found at surveillance. Two patients $(8.3 \%)$ had CRC successfully treated. The average age of patients with dysplasia was 56.1 years, with a mean disease duration of 10.9 years in LSC versus 11.8 years in pancolitis ( $\mathrm{P}$ not significant). Colectomy was not recommended for any patient with flat dysplasia. No patients progressed to high-grade dysplasia or CRC. Patients with pancolitis had a higher incidence of neoplasia (21\% [18 of 86]) than patients with LSC (12\% [6 of 49]; $\mathrm{P}=0.24)$. Forty-one patients (29.5\%) had at least one hyperplastic or inflammatory polyp.

CONCLUSIONS: For the majority of patients who underwent surveillance colonoscopies, their procedures were performed within the recommended time intervals, and biopsy compliance has improved. Dysplasia tended to arise after approximately 10 years of disease duration and in middle age, with flat dysplasia being rare. Interventions resulted in no dysplasia progressing to CRC, implying successful prevention.

Key Words: Colonoscopy; Dysplasia; Surveillance; Ulcerative colitis

Patients with ulcerative colitis (UC) have an increased lifeP time incidence of colorectal cancer compared with the general population (1-4). In a meta-analysis of 194 studies, Eaden et al (3) estimated that the cumulative probability of

\section{Le respect des lignes directrices sur la}

coloscopie de contrôle chez les patients atteints de colite ulcéreuse dans un centre de soins quaternaires au Canada

CONTEXTE : Les patients atteints de colite ulcéreuse (CU) sont fortement prédisposés à la dysplasie colique. Aussi de nombreuses organisations professionnelles sont-elles en faveur de la coloscopie de contrôle en vue de la détection précoce de la dysplasie.

BUTS : L'étude avait pour buts de déterminer si les gastroentérologues pratiquant à l'hôpital Hamilton Health Sciences (Hamilton, Ontario) appliquaient les recommandations de l'Association canadienne de gastroentérologie sur la surveillance de la CU, et d'évaluer, de façon rétrospective, le type de dysplasie relevée, son incidence et l'évolution de l'état de santé des patients présentant de la dysplasie (cancer colorectal [CC], colectomie, récidive de dysplasie).

MÉTHODE : Nous avons procédé à un examen rétrospectif des dossiers de tous les patients atteints de CU, qui ont subi une coloscopie de dépistage à l'hôpital Hamilton Health Sciences, de janvier 1980 à janvier 2005. Les patients ont été classés selon l'étendue de la maladie du côlon : colite gauche (CG), pancolite ou maladie avec cholangite sclérosante primitive concomitante.

RÉSULTATS : Cent quarante et un patients, en tout, répondaient aux critères de sélection. Ils ont subi 921 endoscopies, dont 453 de contrôle, réalisées par 20 endoscopistes. Dans l'ensemble, $90 \%$ des patients ont été soumis au dépistage, et les examens de contrôle ont été effectués au bon moment dans $74 \%$ des cas. Une augmentation statistiquement significative du nombre moyen de biopsies par coloscopie a été observée après la publication des lignes directrices ( $\mathrm{P}<0,01$ dans toutes les catégories). Une dysplasie colique a été détectée chez 24 patients sur 141 (17,0\%); chez 17 d'entre eux $(70,8 \%)$, la découverte s'est faite au moment d'un examen de contrôle. Deux patients $(8,3 \%)$ ont souffert d'un CC, traité avec succès. Lâge moyen des patients présentant une dysplasie était de 56,1 ans, et la durée moyenne de la maladie était de 10,9 ans dans les cas de CG et de 11,8 ans dans les cas de pancolite (P : non significatif). La colectomie n'a été recommandée dans aucun cas de dysplasie plane. Il n'y a pas eu d'évolution vers un degré élevé de dysplasie ou vers le CC, dans les dossiers examinés. Les patients souffrant de pancolite ont connu une incidence plus élevée de néoplasie (21\% [18 sur 86] que les patients souffrant d'une CG (12\% [6 sur 49]; P = 0,24). Un polype hyperplasique ou inflammatoire au moins a été découvert chez 41 patients (29,5\%).

CONCLUSIONS : Dans la plupart des cas, la coloscopie de contrôle a été pratiquée dans les délais recommandés, et il y a eu une amélioration du respect des lignes directrices en ce qui concerne les biopsies. La dysplasie tendait à apparaître après une dizaine d'années de maladie, chez les personnes d'âge moyen, et la fréquence de la dysplasie plane était rare. L'absence d'évolution de la dysplasie vers le CC laisse croire à l'efficacité des interventions préventives.

cancer is $2 \%$ at 10 years, $8 \%$ at 20 years and $18 \%$ at 30 years from symptom onset. Individual studies have estimated the RR of colorectal neoplasia to be between 2.1 and 17.3 (5-7). In patients with longstanding disease, colonoscopy is recommended 
TABLE 1

Patient characteristics in the study population $(n=141)$

\begin{tabular}{|c|c|c|c|}
\hline \multirow[b]{2}{*}{ Characteristic } & \multirow[b]{2}{*}{ Total population } & \multicolumn{2}{|c|}{ Surveillance population } \\
\hline & & Appropriately timed $(n=105)$ & Missed $(n=36)$ \\
\hline Age, years (mean $\pm S D)$ & $55 \pm 17$ & $53 \pm 16$ & $61 \pm 20$ \\
\hline Male sex, \% & 53 & 55 & 47 \\
\hline Colonoscopies (total in study population), mean & 6.6 & 7.1 & 5.3 \\
\hline Surveillance colonoscopies, mean & 3.3 & 3.7 & 1.8 \\
\hline \multicolumn{4}{|l|}{ Disease activity, n (\%) } \\
\hline Primary sclerosing cholangitis & $6(4)$ & $2(2)$ & $4(10)$ \\
\hline Left-sided colitis & $49(35)$ & $35(33)$ & $15(41)$ \\
\hline Pancolitis & $86(61)$ & $68(65)$ & $18(49)$ \\
\hline
\end{tabular}

to survey for flat dysplasia and dysplasia-associated lesions or masses. No randomized clinical trials have demonstrated that this strategy reduces colon cancer mortality (8). Observational studies suggest that patients with UC undergoing surveillance have adenocarcinoma detected at an earlier Duke's stage but have similar disease-specific survival $(9,10)$.

Guidelines from several jurisdictions have endorsed surveillance colonoscopy in patients with UC (11-15). The American Society of Gastrointestinal Endoscopy guidelines advocate annual surveillance colonoscopy beginning eight to 10 years from disease onset. Both Canadian and British guidelines suggest that surveillance colonoscopy should begin eight to 10 years from disease onset for patients with pancolitis and after 15 to 20 years for individuals with left-sided colitis. If no dysplasia is detected, subsequent surveillance colonoscopies should be repeated every three years for 10 years, biennially for the next 10 years and annually thereafter. Patients with primary sclerosing cholangitis (PSC) should undergo colonoscopy annually from the time of diagnosis. At colonoscopy, two to four random biopsies should be taken at $10 \mathrm{~cm}$ intervals, with additional biopsies from suspicious areas (eg, irregular plaques, unusual ulcers or strictures). It has been calculated that 33 and 64 biopsies would be required to detect dysplasia with $90 \%$ and $95 \%$ probability, respectively (16). While there is no age restriction for undergoing colonoscopy, comorbidity and ability to withstand colectomy if dysplasia is detected should be considered on a case-by-case basis.

We sought to determine whether endoscopists at Hamilton Health Sciences (Hamilton, Ontario), a tertiary care teaching hospital, adhere to guidelines for UC colorectal surveillance endorsed by the Canadian Association of Gastroenterology and the Canadian Digestive Health Foundation. The specific aims of the present study were to provide Canadian gastroenterologists with an objective evaluation of their practice, and to determine whether practice patterns have changed since the introduction of the guidelines.

\section{METHODS}

A retrospective chart review to identify patients with UC undergoing screening colonoscopy at Hamilton Health Sciences from January 1980 to January 2005, was performed. The electronic health record was searched using the International Classification of Diseases - Ninth Revision (ICD-9) codes 556.1, 556.2, 556.3, 556.4, 556.5, 556.6, 556.7, 556.8, 556.9, 558.1, 558.2 and 558.9. A manual review of each record retrieved was then undertaken to identify patients with a histologically confirmed diagnosis of UC who had been seen by a physician at Hamilton Health Sciences within three years. Patients were excluded if they had indeterminate colitis or a hereditary polyposis syndrome.

Data extracted from the medical records of all eligible patients included the year of onset of UC symptoms, proximal extent of disease, concomitant diagnosis of PSC, year of first surveillance colonoscopy, subsequent frequency of colonoscopy, number and location of biopsies taken, year and stage of diagnosis of colonic dysplasia/neoplasia, intervention for dysplasia/neoplasia and outcome, and family history of colorectal cancer. Patients were divided into three groups for analysis: concomitant PSC (irrespective of disease extent), left-sided disease (distal to the splenic flexure) and extensive or pancolitis. Extent of disease was classified based on microscopic evidence at initial colonoscopy. If left-sided disease progressed to pancolitis, surveillance colonoscopy was expected to be performed at a frequency appropriate for the latter category.

The appropriateness of biopsy sampling was determined by the proportion of colonoscopies in which at least 32 biopsies were taken. The appropriateness of the interval from disease onset to first surveillance and each subsequent surveillance interval was assessed in accordance with Canadian guidelines. A window of six months was allowed for scheduling. Patients with left-sided disease who progressed to extensive colitis were assessed for appropriateness in the latter category.

Most analyses were descriptive. Unpaired $t$ tests, assuming equal variance and alpha $=0.05$, were used to compare numbers of biopsies before and after the publication of guidelines. All data were analysed using Excel 2003 (Microsoft Corp, USA).

\section{Search results}

\section{RESULTS}

A total of 1469 potentially eligible patients were identified. Of these, 141 who fulfilled eligibility criteria had undergone 921 endoscopies, with 453 performed for surveillance by 20 different gastroenterologists. The remaining 1328 excluded patients were either found to not have UC (438 patients), had undergone colectomy (398 patients), had insufficient duration of disease for screening (278 patients), had inflammatory bowel disease not otherwise specified (68 patients) or subsequently believed to have Crohn's disease (130 patients), or had highgrade dysplasia or colorectal cancer (16 patients). All patients who were eligible for screening had undergone at least one colonoscopy. The characteristics of included patients are summarized in Table 1. Six patients had PSC. Eighty-six patients 
TABLE 2

Compliance of dysplasia surveillance in patients with ulcerative colitis

\begin{tabular}{|c|c|c|c|c|c|c|}
\hline \multirow[b]{2}{*}{ Disease activity } & \multirow[b]{2}{*}{ Patients, n } & \multirow{2}{*}{$\begin{array}{c}\text { Patients with appropriate } \\
\text { surveillance, } \%\end{array}$} & \multirow{2}{*}{$\begin{array}{c}\text { Patients with appropriate } \\
\text { number of biopsies at } \\
\text { surveillance, } \%\end{array}$} & \multicolumn{2}{|c|}{ Biopsies, n (mean \pm SD) } & \multirow[b]{2}{*}{$\mathbf{P}$} \\
\hline & & & & After guidelines & Before guidelines & \\
\hline Pancolitis & 86 & 79.1 & 12.8 & $20.0 \pm 9.9$ & $11.5 \pm 7.6$ & $<0.001$ \\
\hline Left-sided disease & 49 & 69.4 & 10.0 & $17.8 \pm 4.5$ & $9.4 \pm 6.4$ & $<0.001$ \\
\hline $\begin{array}{l}\text { Primary sclerosing } \\
\text { cholangitis }\end{array}$ & 6 & 33.3 & 0 & $15.9 \pm 5.6$ & $9.0 \pm 4.9$ & 0.008 \\
\hline
\end{tabular}

had pancolitis and 49 had left-sided disease. As expected, subjects with pancolitis had undergone more colonoscopies, in part, because surveillance began sooner after disease onset.

\section{Appropriateness of surveillance}

Of the 86 patients with pancolitis, $95 \%$ had an initial screening colonoscopy at the appropriate time and $79 \%$ had subsequent surveillance colonoscopies at appropriate time intervals (Table 2). Of the 49 patients with left-sided disease, $82 \%$ had their initial screening colonoscopy at the recommended time and $69 \%$ had appropriate subsequent surveillance intervals. Only two of the six patients with PSC underwent annual dysplasia surveillance. Compliance with recommended biopsy numbers was only $13 \%$ for patients with pancolitis, $10 \%$ for those with left-sided disease and 0\% for those with PSC. The average number of biopsies taken during surveillance colonoscopy improved after the guidelines were published. The average number of biopsies per colonoscopy increased from 9.0 to 15.9 in patients with $\mathrm{PSC}(\mathrm{P}=0.008)$, from 9.4 to 17.8 in those with left-sided disease $(\mathrm{P}<0.001)$ and from 11.5 to 20.0 in individuals with pancolitis $(\mathrm{P}<0.001)$ (Table 2$)$.

\section{Dysplasia}

In total, colonic dysplasia was detected in 24 of 141 patients (17\%) (Table 3). Nine patients (6\%) had neoplastic lesions detected at a scheduled surveillance colonoscopy after the guidelines were implemented. Of these, three had left-sided disease and six had pancolitis. Two of nine underwent colectomy (one for invasive adenocarcinoma and one for cytologic atypia indeterminate for dysplasia). The remaining patients had a tubular or tubulovillous adenoma managed endoscopically $(n=5)$ or a flat low-grade dysplasia (LGD) left in situ $(n=2)$.

Fifteen patients with UC had dysplasia discovered before publication of the guidelines. Dysplasia was detected at a colonoscopy designated as surveillance in eight patients, and at a colonoscopy performed for symptoms in seven. One patient in the surveillance group and four in the symptomatic group had dysplasia discovered at a colonoscopy performed earlier than would be recommended by guidelines. In two of seven symptomatic patients, dysplasia was discovered at the index colonoscopy. Tubular or tubulovillous adenomas were found in 11 patients. One patient had flat high-grade dysplasia and the remaining three had flat LGD.

The mean $( \pm$ SD) age of patients with dysplasia was $56.1 \pm 16.4$ years. Among these patients, the mean duration of disease was $10.9 \pm 7.9$ years in left-sided colitis versus $11.8 \pm 5.8$ years in pancolitis (P not significant). Patients with pancolitis were more likely to develop neoplasia (21\%) than those with leftsided disease $(12 \%)$, but this did not reach statistical
TABLE 3

Neoplastic lesions found during colonoscopy

\begin{tabular}{|c|c|c|c|c|c|}
\hline \multirow[b]{3}{*}{ Surveillance } & \multicolumn{4}{|c|}{ Lesion type, n } & \multirow[b]{3}{*}{ TVA } \\
\hline & \multirow{2}{*}{$\begin{array}{c}\text { Colorectal } \\
\text { cancer }\end{array}$} & \multicolumn{2}{|c|}{ Dysplasia (grade) } & \multirow{2}{*}{$\begin{array}{c}\text { Tubular } \\
\text { adenoma }\end{array}$} & \\
\hline & & High & Low & & \\
\hline After guideline pub & ation & & & & \\
\hline Pancolitis & 1 & $1^{*}$ & 2 & 2 & 0 \\
\hline Left-sided colitis & 0 & 0 & 0 & 3 & 0 \\
\hline \multicolumn{6}{|c|}{ Before guideline publication } \\
\hline Pancolitis & 0 & 1 & 3 & 7 & 1 \\
\hline Left-sided colitis & 0 & 0 & 0 & 3 & 0 \\
\hline
\end{tabular}

*One patient who had cytological atypia indeterminate for high-grade dysplasia underwent colectomy. TVA Tubulovillous adenoma

significance $(\mathrm{P}=0.24)$. Forty-one patients $(29.5 \%)$ had at least one hyperplastic or inflammatory polyp. None of the patients with LGD were advised to undergo colectomy.

\section{DISCUSSION}

Surveillance for dysplasia remains an important part of the management of chronic UC. Patients with UC are believed to develop colorectal cancer through pathways different from the adenoma-carcinoma sequence seen in the general population (17-19). Because dysplasia can arise in flat mucosa, random biopsies are advocated even in the absence of a visible lesion.

The present study is the first to investigate whether Canadian gastroenterologists adhere to guidelines for dysplasia surveillance in UC. Most eligible patients began surveillance after appropriate disease duration, particularly those with pancolonic involvement. All patients had at least one colonoscopy performed for scheduled surveillance. Although only a minority of patients had an appropriate number of biopsies taken, this improved significantly after Canadian guidelines were published.

Discrepancies among published surveillance guidelines can create confusion and impair overall compliance. For example, Canadian and British guidelines recommend that surveillance colonoscopy begin at eight to 10 years after disease onset for patients with pancolitis and after 15 to 20 years for individuals with left-sided colitis, with subsequent surveillance intervals dictated by disease duration $(11,20)$. However, guidelines issued by the American Gastroenterological Association do not stratify subsequent surveillance by disease duration and recommend that all patients have surveillance every one to two years (13). The Crohn's and Colitis Foundation of America (CCFA) Colon Cancer in Inflammatory Bowel Diseases (IBD) Study Group has recommended that all patients with left-sided or pancolonic UC have surveillance every one to two years 
starting after eight to 10 years of disease duration, but that the interval be extended to one to three years if there are two consecutive negative examinations, then revert to one to two years after 20 years of disease (21). While Canadian and British guidelines recommend four-quadrant biopsies every $10 \mathrm{~cm}$ but do not specify a total number, CCFA guidelines recommend at least 33 biopsies with sampling every $5 \mathrm{~cm}$ in the lower sigmoid and rectum. International consensus on surveillance would limit confusion and produce a clearer message for practicing clinicians.

The number of surveillance biopsies taken from patients in the present study cohort did not comply with guideline requirements. This is consistent with Eaden et al (22), who found that $24 \%$ of British gastroenterologists offered surveillance to patients with left-sided disease and only $2 \%$ took more than 20 biopsies during a surveillance examination. Similarly, Ullman (23) reported an average of $17.5 \pm 8.4$ biopsies per endoscopy in an IBD population. Taken together, these observations are concerning because it has been suggested that one-quarter of UC-associated dysplasia are not visible at routine endoscopy $(24,25)$. Even when performed appropriately, surveillance biopsy protocols sample less than $1 \%$ of the surface area of the colon and can miss dysplasia. A recent analysis of 1339 surveillance colonoscopies in 622 patients by Rubin et al (24) found that only $59 \%$ of dysplastic lesions and $80 \%$ of cancers were visible to the endoscopist - an overall sensitivity of $61 \%$. The cumulative incidence of dysplasia in our study was similar to that observed by Rubin et al (24).

In the present study cohort, dysplasia tended to arise after approximately 10 years of disease duration, and in middle age. There was no difference in disease duration or the incidence of dysplasia between patients with left-sided disease versus pancolitis. However, more advanced lesions were seen in the latter. In an Olmsted County (Minnesota, USA) cohort (26), pancolitis but not left-sided disease, was associated with colorectal cancer with a standardized incidence ratio of 2.4 versus the general population. Based on our findings, a policy of surveillance eight to 10 years after disease presentation for both left-sided and pancolonic UC may be prudent because both populations seem to develop dysplasia after 10 years.

Of the five patients found to have LGD in our cohort, none were recommended to undergo colectomy and none progressed to high-grade dysplasia or cancer. The management of LGD remains controversial, with some experts advocating colectomy and others a strategy of more intense surveillance (27). Early data suggesting high rates of progression to adenocarcinoma have been challenged $(28,29)$. A recent meta-analysis (30) found LGD to be associated with a ninefold RR of cancer and a 12-fold RR of cancer or high-grade dysplasia. Many studies do not distinguish between unifocal or multifocal LGD, and current recommendations advocate colectomy only for multifocal LGD. All of our patients had unifocal LGD.

Our study has several limitations. First, patients who had not been seen by a physician at Hamilton Health Sciences within the past three years were excluded, which biased our sample toward patients more compliant with surveillance. We also did not examine specific obstacles to surveillance and cannot determine why patients or gastroenterologists in our cohort were more or less compliant $(4,31)$. The principal determinants of successful surveillance are believed to include access to accurate expert pathology, convergence with gastroenterologists' practice preferences, availability of resources and patient compliance (32). Second, our results reflect practice at a single teaching centre and are not necessarily applicable to other centres. We do not know the outcome of these excluded UC patients. Finally, we did not assess comorbid illnesses that may limit patients' ability to tolerate colectomy in the event that advanced neoplasia was detected, and may have influenced a decision not to undertake surveillance. Because the mean age of our cohort was only 55 years, however, this is unlikely to explain a significant proportion of noncompliance. Formal registries have been advocated to improve compliance with surveillance guidelines and other metrics of quality of care (33). Adoption of a registry at our institutions may improve compliance and should be investigated further.

\section{CONCLUSION}

The present study shows that dysplasia surveillance in UC patients at a Canadian tertiary care hospital has improved since the publication of Canadian practice guidelines. Continued education of gastroenterologists and IBD patients concerning the importance and pitfalls of surveillance is needed. Barriers to adoption need to be addressed and investigated further, and better consensus among international guidelines is needed. Prospective validation of the effects of increased compliance with colorectal cancer surveillance in IBD patients needs to be conducted before the perceived benefits of the current guidelines can be proven.

ACKNOWLEDGEMENTS: Dr John Marshall acts as the guarantor for the paper.

AUTHOR CONTRIBUTIONS: DK planned the study, identified and assessed eligibility of patients, extracted data and wrote the manuscript. DY identified and assessed eligibility of patients and extracted data. JM planned the study, helped with data analysis and contributed to writing the paper.

\section{REFERENCES}

1. Jess T, Gamborg M, Matzen P, Munkholm P, Sorensen TI. Increased risk of intestinal cancer in Crohn's disease: A meta-analysis of population-based cohort studies. Am J Gastroenterol 2005;100:2724-9.

2. Chambers WM, Warren BF, Jewell DP, Mortensen NJ. Cancer surveillance in ulcerative colitis. Br J Surg 2005;92:928-36.

3. Eaden JA, Abrams KR, Mayberry JF. The risk of colorectal cancer in ulcerative colitis: A meta-analysis. Gut 2001;48:526-35.

4. Rutter MD, Saunders BP, Wilkinson KH, et al. Thirty-year analysis of a colonoscopic surveillance program for neoplasia in ulcerative colitis. Gastroenterology 2006;130:1030-8.

5. Bernstein CN, Blanchard JF, Kliewer E, Wajda A. Cancer risk in patients with inflammatory bowel disease: A population-based study. Cancer 2001;91:854-62.

6. Ekbom A, Helmick C, Zack M, Adami HO. Ulcerative colitis and colorectal cancer. A population-based study. N Engl J Med 1990;323:1228-33.

7. Karlen P, Lofberg R, Brostrom O, Leijonmarck CE, Hellers G,

Persson PG. Increased risk of cancer in ulcerative colitis: A population-based cohort study. Am J Gastroenterol 1999;94:1047-52.

8. Ullman TA. Colonoscopic surveillance in inflammatory bowel disease. Curr Opin Gastroenterol 2005;21:585-8.

9. Choi PM, Nugent FW, Schoetz DJ Jr, Silverman ML, Haggitt RC. Colonoscopic surveillance reduces mortality from 
colorectal cancer in ulcerative colitis. Gastroenterology 1993;105:418-24

10. Hata K, Watanabe T, Kazama S, et al. Earlier surveillance colonoscopy programme improves survival in patients with ulcerative colitis associated colorectal cancer: Results of a 23-year surveillance programme in the Japanese population. Br J Cancer 2003;89:1232-6.

11. Leddin D, Hunt R, Champion M, et al. Canadian Association of Gastroenterology and the Canadian Digestive Health Foundation: Guidelines on colon cancer screening. Can J Gastroenterol 2004;18:93-9.

12. Ullman TA. Colonoscopic surveillance in inflammatory bowel disease. Curr Opin Gastroenterol 2005;21:585-8.

13. Winawer S, Fletcher R, Rex D, et al. Colorectal cancer screening and surveillance: Clinical guidelines and rationale update based on new evidence. Gastroenterology 2003;124:544-60

14. Itzkowitz SH, Present DH. Consensus conference: Colorectal cancer screening and surveillance in inflammatory bowel disease. Inflamm Bowel Dis 2005;11:314-21.

15. Eaden JA, Mayberry JF. Guidelines for screening and surveillance of asymptomatic colorectal cancer in patients with inflammatory bowel disease. Gut 2002;51(Suppl 5):V10-V12.

16. Itzkowitz $\mathrm{SH}$, Harpaz N. Diagnosis and management of dysplasia in patients with inflammatory bowel diseases. Gastroenterology 2004;126:1634-48.

17. Levine JS, Ahnen DJ. Clinical practice. Adenomatous polyps of the colon. N Engl J Med 2006;355:2551-7.

18. Herszenyi L, Miheller P, Tulassay Z. Carcinogenesis in inflammatory bowel disease. Dig Dis 2007;25:267-9.

19. Delaunoit T, Limburg PJ, Goldberg RM, Lymp JF, Loftus EV Jr. Colorectal cancer prognosis among patients with inflammatory bowel disease. Clin Gastroenterol Hepatol 2006;4:335-42.

20. Eaden JA, Mayberry JF. Guidelines for screening and surveillance of asymptomatic colorectal cancer in patients with inflammatory bowel disease. Gut 2002;51(Suppl 5):V10-V12.

21. Itzkowitz SH, Present DH. Consensus conference: Colorectal cancer screening and surveillance in inflammatory bowel disease. Inflamm Bowel Dis 2005;11:314-21.
22. Eaden JA, Ward BA, Mayberry JF. How gastroenterologists screen for colonic cancer in ulcerative colitis: An analysis of performance. Gastrointest Endosc 2000;51:123-8.

23. Ullman TA. Colonoscopic surveillance in inflammatory bowel disease. Curr Opin Gastroenterol 2005;21:585-8.

24. Rubin DT, Rothe JA, Hetzel JT, Cohen RD, Hanauer SB. Are dysplasia and colorectal cancer endoscopically visible in patients with ulcerative colitis? Gastrointest Endosc 2007;65:998-1004.

25. Rutter MD, Saunders BP, Wilkinson KH, Kamm MA, Williams CB, Forbes A. Most dysplasia in ulcerative colitis is visible at colonoscopy. Gastrointest Endosc 2004;60:334-9.

26. Jess T, Loftus EV Jr Velayos FS, et al. Risk of intestinal cancer in inflammatory bowel disease: a population-based study from Olmsted County, Minnesota. Gastroenterology 2006;130:1039-46.

27. Itzkowitz SH, Harpaz N. Diagnosis and management of dysplasia in patients with inflammatory bowel diseases. Gastroenterology 2004;126:1634-48.

28. Lim CH, Dixon MF, Vail A, Forman D, Lynch DA, Axon AT. Ten-year follow up of ulcerative colitis patients with and without low-grade dysplasia. Gut 2003;52:1127-32.

29. Lim CD. Long-term outcome of UC patients with and without lowgrade dysplasia (LGD). Gastroenterology 2001;120:A-141. (Abst)

30. Thomas T, Abrams KA, Robinson RJ, Mayberry JF. Meta-analysis: Cancer risk of low-grade dysplasia in chronic ulcerative colitis. Aliment Pharmacol Ther 2007;25:657-68.

31. Lindberg J, Stenling R, Palmqvist R, Rutegard J. Efficiency of colorectal cancer surveillance in patients with ulcerative colitis: 26 years' experience in a patient cohort from a defined population area. Scand J Gastroenterol 2005;40:1076-80.

32. Connell WR, Lennard-Jones JE, Williams CB, Talbot IC, Price AB, Wilkinson KH. Factors affecting the outcome of endoscopic surveillance for cancer in ulcerative colitis. Gastroenterology 1994;107:934-44

33. Bampton PA, Sandford JJ, Young GP. Achieving long-term compliance with colonoscopic surveillance guidelines for patients at increased risk of colorectal cancer in Australia. Int J Clin Pract 2007;61:510-3. 


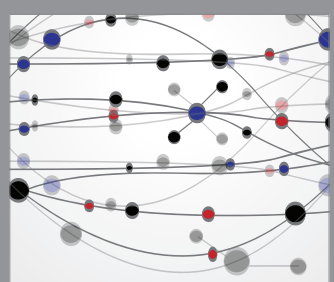

The Scientific World Journal
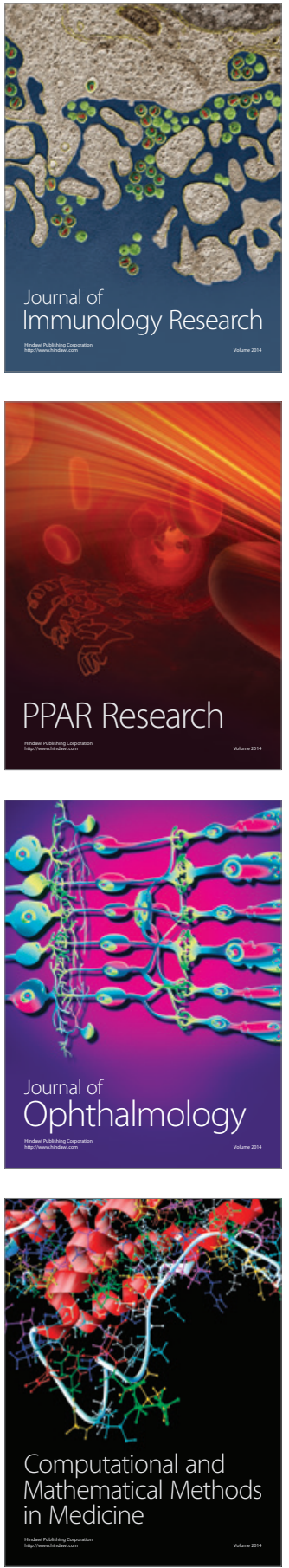

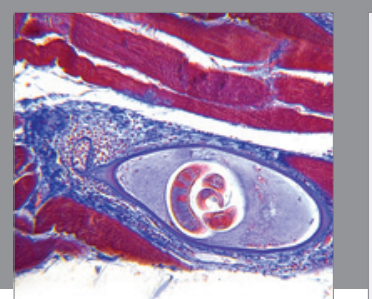

Gastroenterology Research and Practice

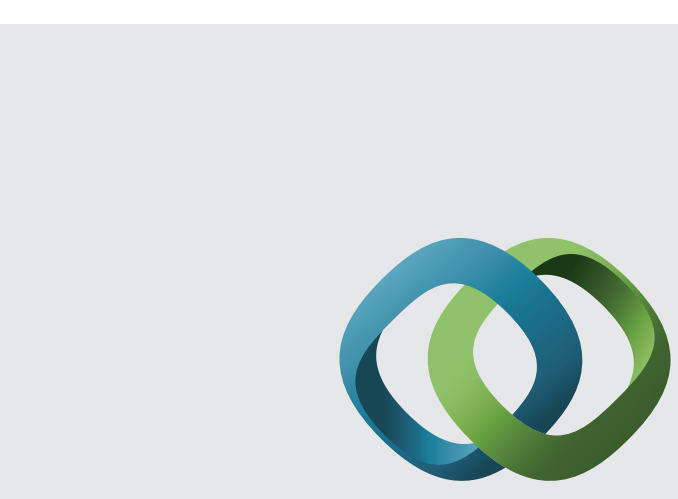

\section{Hindawi}

Submit your manuscripts at

http://www.hindawi.com
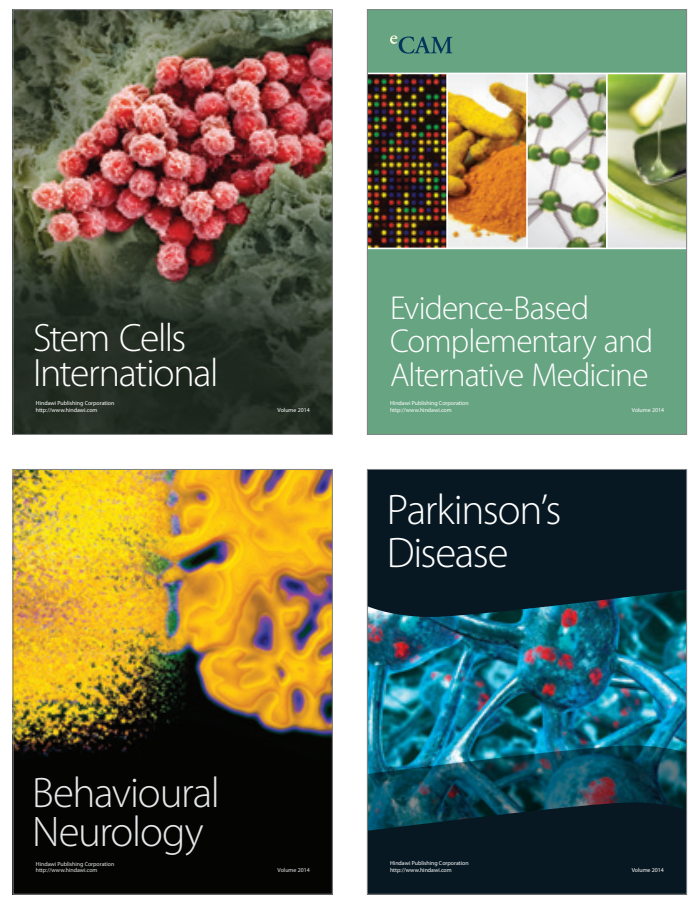
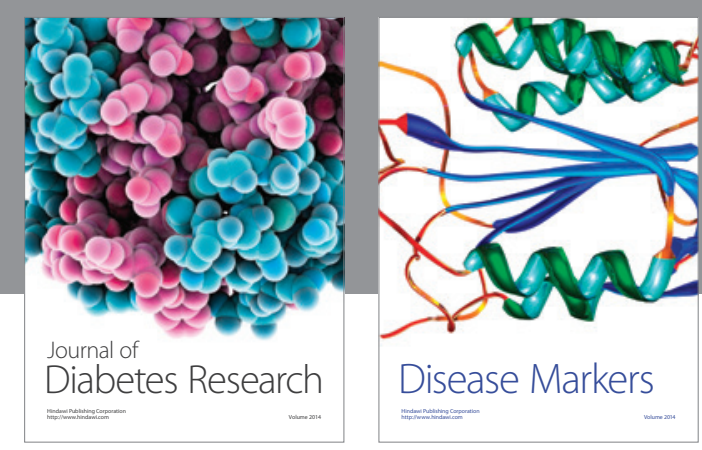

Disease Markers
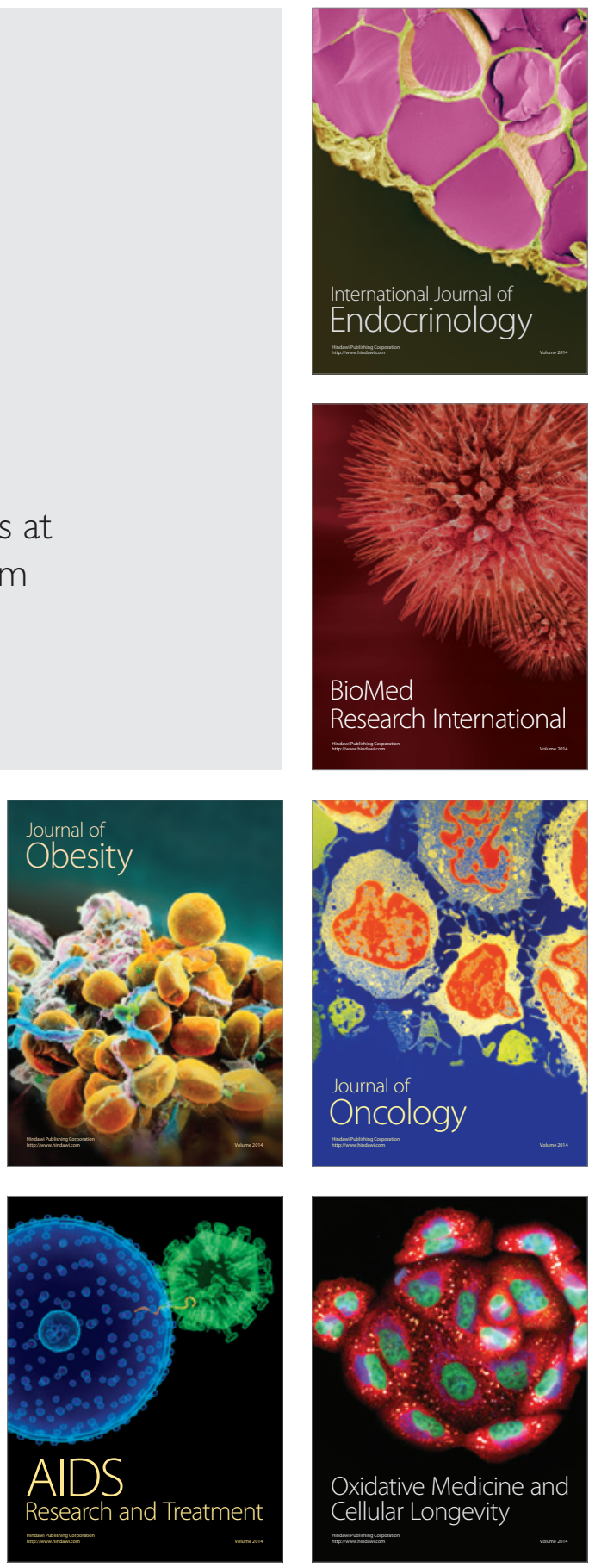